\author{
Vincenzo Raieli \\ Filippo Brighina \\ Giuseppe Calagna \\ Matteo Calia \\ Flavia Consolo \\ Silvio Crinò \\ Mario Demma \\ Dante Ferrara \\ Margherita Francolini \\ Riccardo Lupo \\ Calogero Morreale \\ Domenico Puma \\ Donatella Ragusa \\ Giuseppe Santangelo \\ Franco Serra \\ Giovanni La Pegna
}

Received: 6 June 2005

Accepted in revised form: 19 July 2005

Published online: 21 September 2005

\author{
V. Raieli (凶) \\ Div. NPI, Osp. Ingrassia, \\ Via Giuseppe Pagano 14, \\ I-90129 Palermo, Italy \\ e-mail: vinzi.raielk@inwind.it \\ Tel.: +39-091-7033280 \\ Fax: +39-091-7033192 \\ V. Raieli • F. Brighina $\bullet$ G. Calagna \\ M. Calia $•$ F. Consolo $•$ S. Crinò \\ M. Demma $\bullet$ D. Ferrara $\bullet$ M. Francolini \\ R. Lupo • C. Morreale • D. Puma \\ D. Ragusa $\bullet$ G. Santangelo $\bullet$ F. Serra \\ G. La Pegna* \\ Gruppo Regionale SISC \\ Palermo, Italy \\ *Presidente Sezione Regionale SISC - \\ Caltanissetta
}

\section{"The Headache Week": a useful tool to highlight "invisible" migraineurs}

Headache is a common and disabling disease in every age group. However, epidemiological data show that many affected subjects (about 30\%-70\%) have not ever visited a doctor and have rarely been referred to a pain specialist $(4 \%)[1,2]$. A possible explanation may be unsatisfactory relationships between patients and their physicians [3-5], inducing pessimism and a feeling that no help can be found.

We organised a free meeting in a headache centre for a whole week with the precise aim of better understanding the requests of cephalalgic patients about their headaches. During the established week, several pain experts (belonging to the Italian Society for the Study of Headache) were available to answer questions about paediatric and adult headaches, coming either via phone, mail or direct contact. This "Headache Week" was advertised in journals and posters both in hospitals and outpatient clinics.

During the week, we had 182 contacts: 113 by phone, 58 by direct visit and 11 by mail. There were 136 females and 46 males. Migraine was diagnosed in 133 subjects, chronic daily headache in 19 , not well defined headaches in 26 and other primary headaches in 4 . The more surprising finding was that about $78 \%$ of the population, almost all suffering from severe headaches with respect to frequency of attacks and duration of illness, had not ever visited a headache centre or specialist and had never taken a preventive therapy for their headache. Their chief question was about which headache centre or pain specialist to refer to for ameliorating their headache. In the other $22 \%$ of the subjects, who had previously visited headache centres, the main questions concerned new therapies, potential vascular risks and use of prescription medicines [3-5].

Our obtained data suggest that our initiative to carry out the "Headache Week" has been surprisingly useful, not only to answer the questions of subjects who had already been to pain specialists, but also to highlight the population of cephalalgic patients that never go to a specialist and often cure themselves. Indeed, appropriate diagnosis and management by a headache or pain specialist can give these patients better standard of care, avoiding medication overuse and headache chronicisation. 


\section{References}

1. Lipton RB, Stewart WF, Scher AI (2001) Epidemiology and economic impact of migraine. Curr Med Res Opin 17[Suppl 1]:s4-s12

2. Lipton RB, Scher AI, Kolodner K et al (2002) Migraine in the United States: epidemiology and patterns of health care use. Neurology 58:885-894
3. MacGregor EA (1997) The doctor and the migraine patient: improving compliance. Neurology 48[Suppl 3]:S16-S20

4. Packard RC (1979) What does the headache patient want? Headache 19:370-374
5. Raieli V, Puma D, Eliseo GL, La Franca G et al (2002) Cosa significa la "Cefalea" per il bambino, la madre e il pediatra: aspetti metodologici e dati preliminari. Atti XVI Congr. Naz. SISC, Chieti, pp 449-451 